\title{
The first Triassic vertebrate fossils from Myanmar: Pachypleurosaurs in a marine limestone
}

Khaing Khaing San, Nicholas C. Fraser, Davide Foffa, Olivier Rieppel, and Stephen L. Brusatte Acta Palaeontologica Polonica 64 (2), 2019: 357-362 doi:https://doi.org/10.4202/app.00594.2019

As ecosystems recovered from the end-Permian extinction, many new animal groups proliferated in the ensuing Triassic. Among these were the sauropterygians, reptiles that evolved from terrestrial ancestors and transitioned to a marine environment. The first sauropterygians were small, marine-adapted taxa such as pachypleurosaurs, which are known from Middle-Late Triassic deposits, particularly in the Tethyan realm of Europe, and more recently from Lagerstätten in southwestern China. Here we report two pachypleurosaurs from Myanmar, the first Triassic vertebrate fossils from the country. These specimens demonstrate that their entombing rocks in northern Shan State, which have received less study than terrestrial sediments in southern Shan State and whose ages have long been uncertain, are Triassic. The specimens may be among the oldest pachypleurosaurs globally, potentially corroborating biogeographic scenarios that posit an eastern Tethyan origin for pachypleurosaurs, and raise the potential for future discoveries of well-preserved Triassic reptiles in Myanmar.

Khaing Khaing San [khaingkhaingsan2014@gmail.com], Geology Department, Yadanabon University, Amarapura, Myanmar. Nicholas C. Fraser [nick.fraser@nms.ac.uk ], Davide Foffa [davide.foffa@ed.ac.uk], Stephen L. Brusatte [stephen.brusatte@ed.ac.uk ], School of GeoSciences, University of Edinburgh, Grant Institute, James Hutton Road, Edinburgh EH9 3FE, UK; National Museums of Scotland, Chambers Street, Edinburgh EH1 1JF, UK. Olivier Rieppel [orieppel@ fieldmuseum.org], Center of Integrative Research, The Field Museum, Chicago, Illinois 60605-2496, USA.

This is an open-access article distributed under the terms of the Creative Commons Attribution License (for details please see creativecommons.org), which permits unrestricted use, distribution, and reproduction in any medium, provided the original author and source are credited. 
Fof Full text $(638.0 \mathrm{kB})$ 